\title{
Physiologic Effects of High-Flow Nasal Cannula Oxygen in Critical Care Subjects
}

\author{
Frederic Vargas MD PhD, Mélanie Saint-Leger MD, Alexandre Boyer MD PhD, \\ Nam H Bui MD, and Gilles Hilbert MD PhD
}

\begin{abstract}
INTRODUCTION: High-flow nasal cannula (HFNC) can deliver heated and humidified gas (up to $100 \%$ oxygen) at a maximum flow of $60 \mathrm{~L} / \mathrm{min}$ via nasal prongs or cannula. The aim of this study was to assess the short-term physiologic effects of HFNC. Inspiratory muscle effort, gas exchange, dyspnea score, and comfort were evaluated. METHODS: Twelve subjects admitted to the ICU for acute hypoxemic respiratory failure were prospectively included. Four study sessions were performed. The first session consisted of oxygen therapy given through a high- $\mathrm{F}_{\mathrm{IO} 2}$, non-rebreathing face mask. Recordings were then obtained during periods of HFNC and CPAP at $5 \mathrm{~cm}_{2} \mathrm{O}$ in random order, and final measurements were performed during oxygen therapy delivered via a face mask. Each of these 4 periods lasted $\sim 20 \mathrm{~min}$. RESULTS: Esophageal pressure signals, breathing pattern, gas exchange, comfort, and dyspnea were measured. Compared with the first session, HFNC reduced inspiratory effort (pressure-time product of 156.0 [119.2-194.4] $\mathrm{cm}_{2} \mathrm{O} \times \mathrm{s} / \mathrm{min}$ vs $\left.204.2[149.6-324.7] \mathrm{cm} \mathrm{H}_{2} \mathrm{O} \times \mathrm{s} / \mathrm{min}, P<.01\right)$ and breathing frequency $(P<.01)$. No significant differences were observed between HFNC and CPAP for inspiratory effort and breathing frequency. Compared with the first session, $\mathrm{P}_{\mathrm{aO} 2} / \mathrm{F}_{\mathrm{IO} 2}$ increased significantly with $\mathrm{HFNC}$ (167 [157$184] \mathrm{mm} \mathrm{Hg}$ vs $156[110-171] \mathrm{mm} \mathrm{Hg}, P<.01)$. CPAP produced significantly greater $\mathrm{P}_{\mathrm{aO} 2} / \mathrm{F}_{\mathrm{IO} 2}$ improvement than did HFNC. Dyspnea improved with HFNC and CPAP, but this improvement was not significant. Subject comfort was not different across the 4 sessions. CONCLUSIONS: Compared with conventional oxygen therapy, HFNC improved inspiratory effort and oxygenation. In subjects with acute hypoxemic respiratory failure, HFNC is an alternative to conventional oxygen therapy. (ClinicalTrials.gov registration NCT01056952.) Key words: high-flow nasal cannula; continuous positive airway pressure; oxygen therapy; acute hypoxemic respiratory failure; inspiratory effort. [Respir Care 2015;60(10):1369-1376. (C) 2015 Daedalus Enterprises]
\end{abstract}

\section{Introduction}

Supplemental oxygen administration is the first-line treatment for acute hypoxemic respiratory failure. Oxygen is usually delivered through a high- $\mathrm{F}_{\mathrm{IO}_{2}}$, non-rebreathing face mask. ${ }^{1-3}$ One limitation with conventional oxygen administration is the substantial mismatch between oxygen flow and the patient's inspiratory flow. The patient's peak

The authors are affiliated with the Service de Réanimation Médicale, Hôpital Pellegrin-Tripode, Bordeaux, France. Drs Vargas and Hilbert are also affiliated with the Centre de Recherche Cardio-thoracique, CIC 0005, Université de Bordeaux, Bordeaux, France.

This study was supported by a research grant from Fisher \& Paykel Healthcare. The authors have disclosed no conflicts of interest. inspiratory flow may vary between 30 and $120 \mathrm{~L} / \mathrm{min}$ during respiratory failure. ${ }^{2,3}$ An alternative to conventional oxygen therapy has been developed. High-flow nasal cannula (HFNC) is a technique that can deliver heated and humidified gas (up to $100 \%$ oxygen) at a maximum flow of $60 \mathrm{~L} / \mathrm{min}$ via nasal prongs or cannula. ${ }^{4-6}$ Studies have shown that HFNC can generate flow-dependent, low-level positive airway pressure (PAP) ${ }^{6-9}$ reduce airway resis-

\footnotetext{
Correspondence: Frederic Vargas MD PhD, Service de Réanimation Médicale, Centre Hospitalo-Universitaire Pellegrin-Tripode, Place Amélie Raba Léon, 33076 Bordeaux Cedex, France. E-mail: frederic.vargas@chu-bordeaux.fr.
}

DOI: $10.4187 /$ respcare. 03814 
tance ${ }^{10,11}$ and flush nasopharyngeal dead space. ${ }^{12-14}$ Positive expiratory pressure may have a number of benefits in respiratory failure, including improved ventilation/perfusion matching with improved oxygenation, reduced airway resistance, and reduced work of breathing. Moreover, HFNC may improve oxygen administration by decreasing oxygen dilution, decreasing dead space, and providing high levels of humidification. Data on ICU subjects with respiratory failure are scarce. ${ }^{15-18}$ In these studies, HFNC had a beneficial effect on clinical signs and oxygenation in subjects with acute respiratory failure. However, to our knowledge, a rigorous assessment of inspiratory effort and oxygenation has not been performed.

See the Related Editorial on Page 1522

The aim of this study was to assess the short-term physiologic effects of HFNC compared with those of conventional oxygen therapy delivered via a face mask in subjects admitted to an ICU for acute hypoxemic respiratory failure. We also compared HFNC with CPAP at $5 \mathrm{~cm} \mathrm{H}_{2} \mathrm{O}$. Our hypothesis was that HFNC and CPAP would reduce the inspiratory effort and subsequently the breathing frequency and improve oxygenation and comfort better than standard oxygen.

\section{Methods}

\section{Subjects}

Consecutives subjects admitted to the ICU between January 2011 and January 2012 for acute hypoxemic respiratory failure were considered eligible for the study. Inclusion criteria were: acute hypoxemic respiratory failure defined by $\mathrm{P}_{\mathrm{aO}_{2}} / \mathrm{F}_{\mathrm{IO}_{2}} \leq 300 \mathrm{~mm} \mathrm{Hg}$ on oxygen and lung infiltrates by chest radiograph. ${ }^{3,19}$ Subjects with tracheostomies were not eligible for the study. Exclusion criteria were: $<18$ y of age, chronic retention of $\mathrm{CO}_{2}$, respiratory acidosis ( $\mathrm{pH}<7.35$ and $\mathrm{P}_{\mathrm{aCO}_{2}}>45 \mathrm{~mm} \mathrm{Hg}$ ), factors related to insertion of an esophageal catheter (recent gastric or esophageal surgery, active upper gastrointestinal bleeding, poor cooperation), excessive amounts of respiratory secretions, systolic blood pressure of $<90 \mathrm{~mm} \mathrm{Hg}$, ventricular arrhythmia, encephalopathy or coma, life-threatening hypoxemia $\left(\mathrm{P}_{\mathrm{aO}_{2}} / \mathrm{F}_{\mathrm{IO}_{2}}<100 \mathrm{~mm} \mathrm{Hg}\right)$, and decision to limit lifesupport treatments in the ICU. ${ }^{3}$ An independent review board (Comité de Protection des Personnes Sud-Ouest et Outre Mer) approved the study. Written informed consent was obtained from each subject or next of kin before inclusion.

\section{Study Design}

Protocol. Subjects meeting eligibility criteria were enrolled in the study. Four study sessions with subjects in a semirecumbent position were performed. The first session

\section{QUICK LOOK}

\section{Current knowledge}

Heated and humidified high-flow oxygen has been shown to improve oxygenation and reduce minute ventilation requirements in patients with respiratory disease. The mechanisms of action include the washout of anatomical dead space of the upper airway, development of a low level of PEEP, and meeting inspiratory demands with sufficient flow.

\section{What this paper contributes to our knowledge}

In a small group of 12 subjects, the delivery of heated and humidified oxygen with high-flow nasal cannula (HFNC) was superior to high-flow oxygen via a nonrebreathing mask. Breathing frequency and inspiratory effort were reduced with HFNC compared with the non-rebreathing mask. However, CPAP at $5 \mathrm{~cm} \mathrm{H}_{2} \mathrm{O}$, was superior to $\mathrm{HFNC}$ in improving oxygenation.

consisted of conventional oxygen therapy via a high- $\mathrm{F}_{\mathrm{IO}_{2}}$, non-rebreathing face mask. Recordings were then obtained during sessions of HFNC and CPAP, in random order, and the final measurements were taken during oxygen therapy delivered via the high- $\mathrm{F}_{\mathrm{IO}_{2}}$, non-rebreathing face mask. Each of these 4 periods lasted $\sim 20 \mathrm{~min}$, so the measurements were completed in $<2 \mathrm{~h}$.

Non-Rebreathing Mask. Conventional oxygen was given via a high- $\mathrm{F}_{\mathrm{IO}_{2}}$, non-rebreathing face mask (Hudson RCI/Teleflex Medical, High Wycombe, United Kingdom). The goal was to achieve an $\mathrm{S}_{\mathrm{pO}_{2}}$ of $>90 \%$. At the end of the first non-rebreathing mask session, the $\mathrm{F}_{\mathrm{IO}_{2}}$ was measured using a portable oxygen analyzer (MiniOX I, Mine Safety Appliances, Pittsburgh, Pennsylvania). The tip of the oxygen analyzer was introduced via a small hole in the face mask. ${ }^{17}$

HFNC Device. We used the Optiflow HFNC device (Fisher \& Paykel Healthcare, Auckland, New Zealand). This device consists of an air-oxygen blender with adjustable $\mathrm{F}_{\mathrm{IO}_{2}}$ that delivers a modifiable gas flow to a heated chamber (MR850 pass-over humidifier, Fisher \& Paykel Healthcare), where the gas is heated and humidified. The gas mixture is then delivered at $37^{\circ} \mathrm{C}$ via short, wide-bore, bi-nasal prongs. For all subject, gas flow was set at $60 \mathrm{~L} / \mathrm{min}$. We used the largest cannula tolerable for each individual subject.

CPAP Device. The CPAP device used was the BiPAP Vision (Philips Respironics, Murrysville, Pennsylvania) fit- 
ted to a face mask (Mirage, ResMed, Sydney, Australia) and connected to an active humidification system (Fisher \& Paykel Healthcare). The size of the face mask was chosen to optimize subject comfort while minimizing air leaks. For all subjects, CPAP was set at $5 \mathrm{~cm} \mathrm{H}_{2} \mathrm{O}$.

The $\mathrm{F}_{\mathrm{IO}_{2}}$ measured at the end of the first non-rebreathing mask session served as a reference. We set the same level for HFNC and CPAP sessions, and we checked it at the end of every session using the portable oxygen analyzer.

\section{Measurements}

Esophageal Pressure. Esophageal pressure $\left(\mathrm{P}_{\mathrm{es}}\right)$ was measured using a single-balloon catheter (Marquat, BoissySaint-Léger, France) inserted through the nose (after topical anesthesia) and advanced until the distal balloon was in the middle portion of the esophagus. The balloon was filled with $1 \mathrm{~mL}$ of air and connected to a pressure transducer at $\pm 100 \mathrm{~cm} \mathrm{H}_{2} \mathrm{O}$ (Biopac Systems, Goleta, California). An occlusion test was performed to assess appropriate placement of the esophageal balloon. Gentle manual pressure on the abdomen was applied to verify the absence of pressure fluctuations. ${ }^{20,21}$ Pressure was digitized on a personal computer at $200 \mathrm{~Hz}$ and sampled using an analog-to-digital converter system (MP100, Biopac Systems).

Gas Exchange and Hemodynamic Parameters. An indwelling catheter was inserted into a radial artery to allow blood gas analysis and systemic blood pressure monitoring at the end of each test period except the final non-rebreathing mask session. Blood gases were measured using an ABL520 analyzer (Radiometer, Brønshøj, Denmark). Systolic and diastolic arterial blood pressures were continuously monitored. $\mathrm{S}_{\mathrm{pO}_{2}}$ was monitored continuously. Heart rate and breathing frequency were monitored using an ICU monitor.

Comfort and Dyspnea. Subject comfort and dyspnea were assessed at the end of each test period. A member of the team (MS-L) asked the subjects to grade the comfort of the different devices using the following scale: 1 , severe discomfort; 2 , discomfort; 3 , acceptable level of comfort; 4, good level of comfort; and 5, very good level of comfort. ${ }^{22}$ Dyspnea was assessed using a visual analog scale.

Data Collection and Recordings. Age, sex, primary diagnosis of acute hypoxemic respiratory failure, $\mathrm{P}_{\mathrm{aO}} / \mathrm{F}_{\mathrm{IO}_{2}}$, and severity of illness assessed using Simplified Acute Physiology Score II were recorded upon enrollment. Data were taken during the last $5 \mathrm{~min}$ of stable breathing pattern. After elimination of artifacts produced by coughing and esophageal spasms, mean values were computed over 10-30 consecutive breaths and used for the analysis. To estimate the inspiratory effort, we determined the $\mathrm{P}_{\mathrm{es}}$ and the esophageal pressure-time product $\left(\mathrm{PTP}_{\mathrm{es}}\right) . \mathrm{PTP}_{\mathrm{es}} /$ breath was obtained by measuring the area under the $\mathrm{P}_{\mathrm{es}}$ signal from the onset of its negative deflection to its return to baseline. The average $\mathrm{PTP}_{\mathrm{es}}$ /breath $\left(\mathrm{cm} \mathrm{H}_{2} \mathrm{O} \times \mathrm{s}\right)$ was multiplied by the subject's own breathing frequency to obtain $\mathrm{PTP}_{\mathrm{es}} / \mathrm{min}\left(\mathrm{cm} \mathrm{H}_{2} \mathrm{O} \times \mathrm{s} / \mathrm{min}\right)$. We recorded the frequency by the variations in $\mathrm{P}_{\mathrm{es}}$.

Statistical Analysis. Data are reported as the median and interquartile range. We compared the values obtained during the HFNC, CPAP, and first non-rebreathing mask test periods. The small sample size required the use of nonparametric tests. The Friedman test was used for repeated-measures analysis of variance by ranks, and pairwise comparisons were conducted using the Wilcoxon test. The different pairwise comparisons were: HFNC versus first non-rebreathing mask session and HFNC versus CPAP. Because of multiple comparisons, statistical significance was adjusted using the Bonferroni correction. $P<.01$ was considered statistically significant.

\section{Results}

The main baseline characteristics of subjects are reported in Table 1.

\section{Inspiratory Effort}

Table 2 lists the main inspiratory effort data, and Figure 1 shows the individual $\mathrm{PTP}_{\mathrm{es}} / \mathrm{min}$ values. Compared with the first non-rebreathing mask session, HFNC reduced the inspiratory effort, as indicated by the reduction in $\mathrm{P}_{\mathrm{es}}$, $\mathrm{PTP}_{\mathrm{es}} /$ breath, and $\mathrm{PTP}_{\mathrm{es}} / \mathrm{min}(P<.01)$. With CPAP, the inspiratory effort was reduced to a similar extent as with HFNC.

\section{Effects on Oxygenation and Ventilation}

HFNC caused a significant reduction in median breathing frequency compared with the first non-rebreathing mask session (25 [21-33] breaths/min versus 23 [18-25] breaths/min, $P<.01)$. The difference between HFNC and CPAP was not significant $(23[18-25]$ breaths/min versus 21 [21-32] breaths/min, $P=$.9) (Fig. 2). Arterial blood gas values were obtained for all subjects. However, gas exchange measurements were not performed in the final non-rebreathing mask session. Table 2 reports arterial blood gas parameters during the study periods. Figure 3 depicts a schematic representation of individual changes in $\mathrm{P}_{\mathrm{aO}_{2}} / \mathrm{F}_{\mathrm{IO}_{2}}$. Compared with the first non-rebreathing mask session, $\mathrm{P}_{\mathrm{aO}_{2}} / \mathrm{F}_{\mathrm{IO}_{2}}$ increased significantly with HFNC $(\sim 10 \%)$. However, CPAP produced a significantly greater improvement in $\mathrm{P}_{\mathrm{aO}_{2}} / \mathrm{F}_{\mathrm{IO}_{2}}$ than did HFNC $(P<.01)$. 
Table 1. Subject Characteristics at Enrollment

\begin{tabular}{|c|c|c|c|c|c|}
\hline Subject & Age (y) & Sex & SAPS II & $\mathrm{P}_{\mathrm{aO}_{2}} / \mathrm{F}_{\mathrm{IO}_{2}}(\mathrm{~mm} \mathrm{Hg})$ & Primary Diagnosis \\
\hline 1 & 71 & Male & 84 & 101 & Heart failure/CAP \\
\hline 2 & 61 & Male & 76 & 200 & CAP \\
\hline 3 & 51 & Male & 35 & 135 & CAP \\
\hline 4 & 58 & Male & 35 & 145 & CAP \\
\hline 5 & 68 & Female & 29 & 197 & CAP \\
\hline 6 & 74 & Female & 62 & 170 & Immunosuppressed with pulmonary infiltrates and fever \\
\hline 7 & 61 & Male & 50 & 242 & Immunosuppressed with pulmonary infiltrates and fever \\
\hline 8 & 46 & Male & 49 & 261 & Health-care-associated pneumonia \\
\hline 9 & 65 & Male & 37 & 169 & Nosocomial pneumonia \\
\hline 10 & 59 & Male & 26 & 170 & CAP \\
\hline 11 & 78 & Male & 46 & 186 & Immunosuppressed with pulmonary infiltrates and fever \\
\hline 12 & 84 & Male & 49 & 186 & CAP \\
\hline Median (IQR) & $63(59-73)$ & & $48(35-56)$ & $178(157-199)$ & \\
\hline \multicolumn{6}{|c|}{$\begin{array}{l}\text { SAPS II = Simplified Acute Physiology Score II } \\
\text { CAP = community-acquired pneumonia } \\
\text { IQR }=\text { interquartile range }\end{array}$} \\
\hline
\end{tabular}

Table 2. Inspiratory Effort, Arterial Blood Gas Parameters, Comfort, and Dyspnea Score During Study Periods

\begin{tabular}{|c|c|c|c|c|}
\hline Parameter & $\begin{array}{l}\text { Initial Non-Rebreathing } \\
\text { Mask }\end{array}$ & HFNC & CPAP & $\begin{array}{c}\text { Final Non-Rebreathing } \\
\text { Mask }\end{array}$ \\
\hline $\mathrm{P}_{\mathrm{es}}, \mathrm{cm} \mathrm{H}_{2} \mathrm{O}$ & $10.7(7.9-14.8)$ & $9.4(7.0-9.8)^{*}$ & $9.1(6.9-12.2) \dagger$ & $10.7(7.9-14.9)$ \\
\hline $\mathrm{PTP}_{\mathrm{es}} /$ breath, $\mathrm{cm} \mathrm{H}_{2} \mathrm{O} \times \mathrm{s}$ & $9.3(6.7-10.0)$ & $7.6(4.7-8.6)^{*}$ & $9.0(6.9-12.2) \dagger$ & $9.4(7.0-10.2)$ \\
\hline $\mathrm{PTP}_{\mathrm{es}} / \mathrm{min}, \mathrm{cm} \mathrm{H}_{2} \mathrm{O} \times \mathrm{s} / \mathrm{min}$ & $204.2(149.6-324.7)$ & $156.0(119.2-194.4)^{*}$ & $152.5(102.5-205.0) \dagger$ & $206.0(149.5-310.0)$ \\
\hline $\mathrm{pH}$ & $7.45(7.43-7.48)$ & $7.43(7.41-7.47)$ & $7.43(7.42-7.46)$ & ND \\
\hline $\mathrm{P}_{\mathrm{aO}_{2}}, \mathrm{~mm} \mathrm{Hg}$ & $90(76-114)$ & $101(85-127)^{*}$ & $134(119-161) \dagger$ & ND \\
\hline $\mathrm{P}_{\mathrm{aCO}_{2}}, \mathrm{~mm} \mathrm{Hg}$ & $35(32-39)$ & $37(33-41)$ & $35(33-41)$ & ND \\
\hline $\mathrm{F}_{\mathrm{IO}_{2}}$ & $0.65(0.55-0.77)$ & $0.61(0.50-0.75)$ & $0.60(0.50-0.73)$ & ND \\
\hline $\mathrm{P}_{\mathrm{aO}_{2}} / \mathrm{F}_{\mathrm{IO}_{2}}, \mathrm{~mm} \mathrm{Hg}$ & $156(110-171)$ & $167(157-184)^{*}$ & $228(205-269) \dagger$ & ND \\
\hline Comfort score & $3.5(3-4)$ & $4(4-4)$ & $3(3-4)$ & $3.5(3-4)$ \\
\hline Dyspnea score & $35(16-50)$ & $14(8-28)$ & $25(12-55)$ & \\
\hline $\begin{array}{l}\text { All dates are reported as median (interc } \\
* P<.01 \text { vs first non-rebreathing mask } \\
\dagger P=\text { not significant vs HFNC. } \\
\text { HFNC = high-flow nasal cannula } \\
\mathrm{P}_{\mathrm{es}}=\text { esophageal pressure } \\
\text { PTP }_{\mathrm{es}}=\text { pressure-time product } \\
\mathrm{ND}=\text { no data }\end{array}$ & ange). & & & \\
\hline
\end{tabular}

\section{Hemodynamic Parameters}

Neither mean arterial pressure nor heart rate changed significantly (Table 3 ).

\section{Comfort and Dyspnea Score}

As shown in Table 2, subject comfort was not different in the 4 sessions. However, dyspnea decreased with HFNC and CPAP, but this improvement was not significant. Seven subjects preferred HFNC, 2 subjects preferred oxygen therapy delivered via a face mask, and one subject found CPAP more comfortable. Two subjects perceived no difference.

\section{Discussion}

\section{Main Study Results}

Compared with conventional oxygen therapy via a face mask, HFNC resulted in less inspiratory effort and a slight but significant increment in $\mathrm{P}_{\mathrm{aO}_{2}} / \mathrm{F}_{\mathrm{IO}_{2}}$. CPAP produced a significantly greater improvement in $\mathrm{P}_{\mathrm{aO}_{2}} / \mathrm{F}_{\mathrm{IO}_{2}}$ than did HFNC. Tolerance was similar with the 2 methods. Dyspnea improved with HFNC, but this improvement was not significant. 


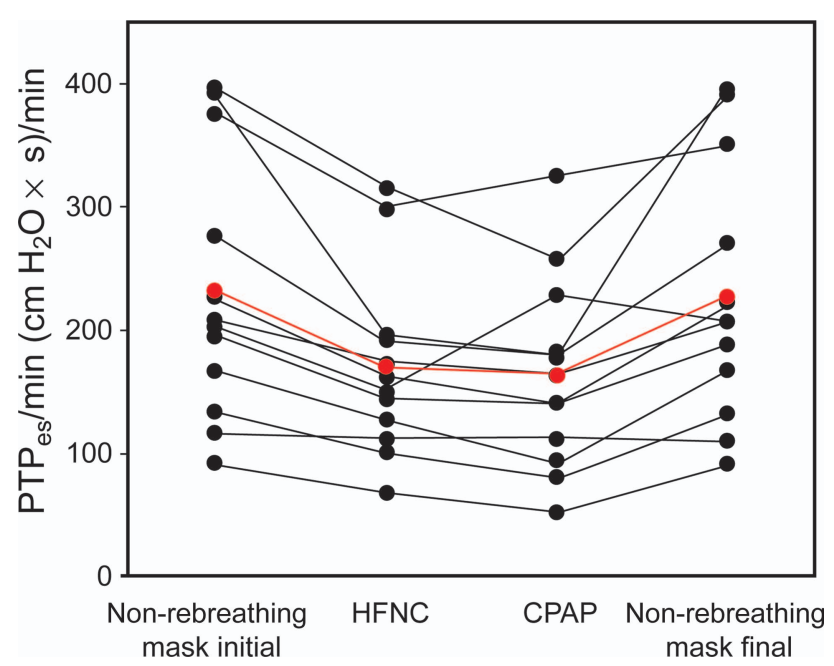

Fig. 1. Individual changes in the esophageal pressure-time product $\left(\mathrm{PTP}_{\text {es }}\right) / \mathrm{min}$ during the 4 periods. The red line represents the mean values. PTP $\mathrm{Ps} / \mathrm{min}$ decreased in all subjects except one with high-flow nasal cannula (HFNC) compared with conventional $\mathrm{O}_{2}$ therapy delivered via a face mask (first non-rebreathing mask session). CPAP produced unloading similar to HFNC.

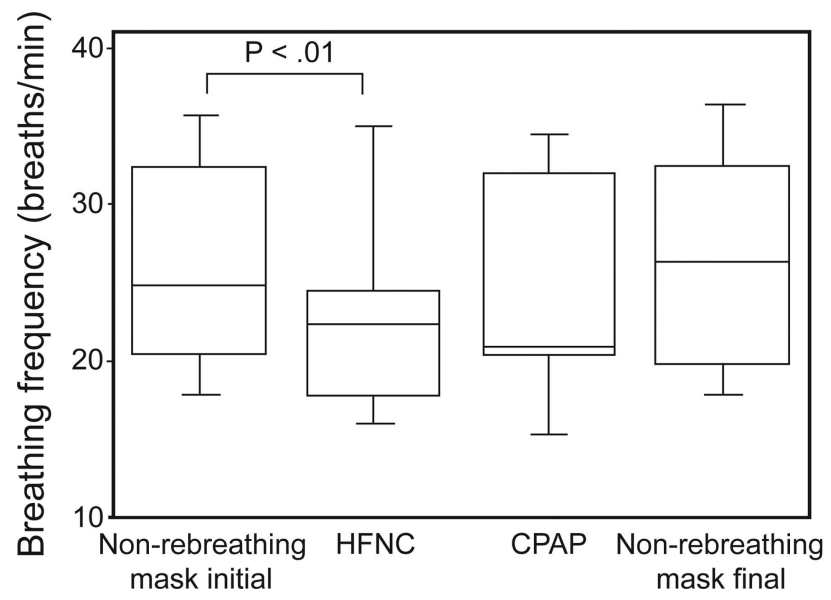

Fig. 2. Box plots summarizing breathing frequency variation during different respiratory sessions. Box plots show median, interquartile range, and outliers (5th to 95th percentiles) of frequency in different periods. HFNC $=$ high-flow nasal cannula.

\section{Inspiratory Effort}

To our knowledge, this is the first study evaluating the effects of HFNC on inspiratory effort. Nevertheless, we found in the literature indirect evidence of inspiratory effort improvement. Sztrymf et al ${ }^{15}$ reported their experience with HFNC in 20 subjects with acute hypoxemic respiratory failure. After subjects were placed on HFNC, respiratory distress was rapidly alleviated, with a significant decrease in breathing frequency and a significant reduction in supraclavicular retraction and thoracoabdominal asynchrony. ${ }^{15}$ In a larger cohort of subjects, the same

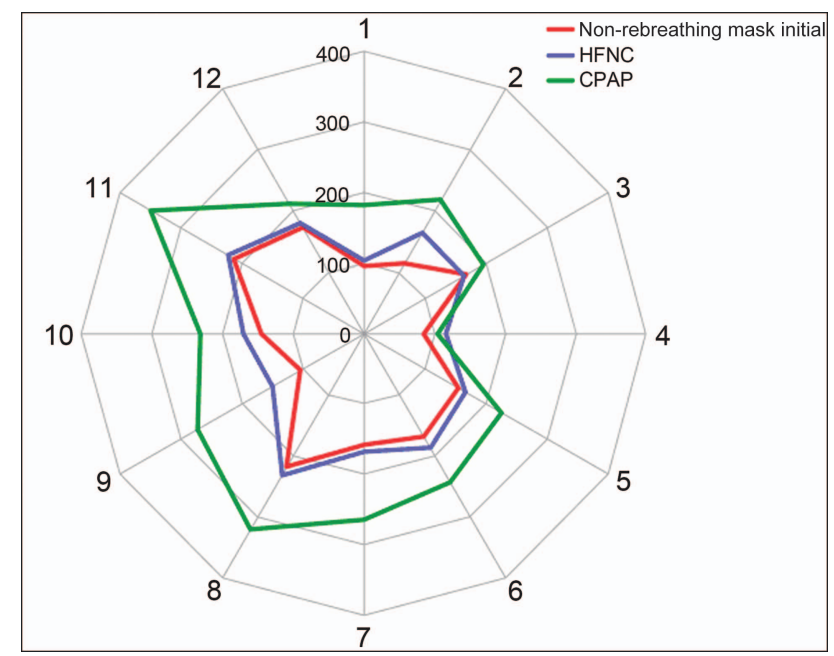

Fig. 3. Schematic representation of individual changes in $\mathrm{P}_{\mathrm{aO}_{2}} / \mathrm{F}_{\mathrm{IO}_{2}}$. High-flow nasal cannula (HFNC) induced a significant change in $\mathrm{P}_{\mathrm{aO}_{2}} / \mathrm{F}_{\mathrm{IO}_{2}}$ compared with $\mathrm{O}_{2}$ therapy delivered via a face mask (first non-rebreathing mask session). However, CPAP provided the greatest improvement in $\mathrm{P}_{\mathrm{aO}_{2}} / \mathrm{F}_{1 \mathrm{I}_{2}}$. Lines numbered 1-12 represent the 12 subjects studied. The concentric values (100-400) denote $\mathrm{P}_{\mathrm{aO}_{2}} / \mathrm{F}_{1 \mathrm{O}_{2}}$ obtained with each device.

team confirmed the rapid alleviation of respiratory distress in more severe subjects. ${ }^{16}$ Several mechanisms may explain the effect of HFNC. The most obvious technique for minimizing the work of breathing during spontaneous ventilation is to decrease airway resistance and recruit collapsed alveolar units. It has been demonstrated that HFNC generates a certain amount of PAP. ${ }^{6-9}$ In subjects recovering from cardiac surgery, a mean PAP of $2.7 \mathrm{~cm} \mathrm{H}_{2} \mathrm{O}$ was measured at $35 \mathrm{~L} / \mathrm{min}$ with the mouth closed. ${ }^{7}$ Chanques et $\mathrm{al}^{9}$ confirmed that HFNC was able to provide a low PAP $\left(<4 \mathrm{~cm} \mathrm{H}_{2} \mathrm{O}\right)$.

An increase in airway resistance has been described with cold- and dry-air inhalation. ${ }^{23,24}$ This may cause a modest increase in ventilatory loading. A heated humidifier noticeably provides much higher levels of humidity. ${ }^{25}$ One may hypothesize that, during acute hypoxemic respiratory failure, humidified HFNC could decrease airway resistance compared with a poorly humidified conventional oxygen therapy device. ${ }^{26}$ Shepard and Burger ${ }^{10}$ demonstrated that, during inspiration, the nose behaves like a variable resistor with a collapsible segment, limiting inspiratory air flow. It is possible that by delivering inspiratory flows higher than those generated by a patient, HFNC opposes this increase in inspiratory resistance, thus reducing the work of breathing.

$\mathbf{P}_{\text {aO2 }} / \mathrm{F}_{\text {IO2 }}$

We found that HFNC slightly but significantly increased $\mathrm{P}_{\mathrm{aO}_{2}} / \mathrm{F}_{\mathrm{IO}_{2}}$ compared with conventional oxygen 
Table 3. Mean Arterial Blood Pressure and Heart Rate

\begin{tabular}{lcrrr}
\hline \hline \multicolumn{1}{c}{ Parameter } & $\begin{array}{c}\text { First Non-Rebreathing } \\
\text { Mask Session }\end{array}$ & HFNC & CPAP & $\begin{array}{r}\text { Final Non-Rebreathing } \\
\text { Mask Session }\end{array}$ \\
\hline Heart rate, beats/min & $90(80-102)$ & $88(82-100)$ & $94(78-100)$ & $91(82-101)$ \\
Mean arterial blood pressure, mm Hg & $91(84-93)$ & $91(83-97)$ & $87(83-102)$ & $92(84-98)$ \\
Values are presented as median (interquartile range). & & & .90 \\
HFNC = high-flow nasal cannula & & & \\
\hline
\end{tabular}

therapy. Frat et al ${ }^{27}$ showed that HFNC significantly improved oxygenation and tachypnea compared with standard oxygen therapy in subjects with acute hypoxemic respiratory failure. HFNC improves oxygenation by various mechanisms, such as decreasing oxygen dilution, reducing dead space, and increasing end-expiratory lung volume and tidal volume. ${ }^{8-11}$ Corley et $\mathrm{al}^{8}$ used electrical lung impedance tomography to assess changes in lung volume. ${ }^{28,29}$ They showed that HFNC was associated with an increase in end-expiratory lung volume and confirmed the generation of positive oropharyngeal pressure reported in earlier studies. Moreover, they reported a significant correlation between end-expiratory lung impedance and airway pressure and demonstrated that at least part of the improvement in oxygenation in subjects with acute hypoxemic respiratory failure was due to alveolar recruitment. ${ }^{8}$

It is important to discuss the greater improvement in $\mathrm{P}_{\mathrm{aO}_{2}} / \mathrm{F}_{\mathrm{IO}_{2}}$ with CPAP $(5 \mathrm{~cm} \mathrm{H} \mathrm{O})$ compared with HFNC. In patients with acute hypoxemic respiratory failure, CPAP increases functional residual capacity and displaces ventilation up from the lower flat portion of the respiratory system pressure-volume curve into a more linear portion. Through this well-known mechanism, CPAP improves oxygenation. ${ }^{30-32}$ Although studies have demonstrated that HFNC is associated with generation of significant positive expiratory pressure, ${ }^{6-8} \mathrm{PAP}$ is widely influenced by numerous factors. The benefits of PAP are likely to be greatest in those patients using high flows and breathing with the mouth closed. However, in our study, we used the highest possible flow, and all our subjects breathed with the mouth closed. In addition, the generated expiratory pharyngeal pressure is significantly different between sexes, with males tending to have lower PAPs than females. Two possible explanations for this discrepancy exist: PAP is influenced first by nasopharyngeal size and second by leaks from the nose. ${ }^{6}$ In our physiologic study, the majority of our subjects (10/12) were men. So, HFNC probably generates a low PAP, but it is highly dependent upon numerous factors: flow, gender, leaks from the nose, and whether the mouth is open or closed. ${ }^{9}$

\section{Breathing Frequency}

In our study, HFNC was associated with a decrease in frequency. A previous review found variations in frequency response to $\mathrm{HFNC}^{33}$ : in most studies, mean frequency decreased. There are probably several competing explanations: a decrease in work of breathing and improvement in oxygenation.

\section{Comfort}

Comfort scores were not significantly different under the 3 oxygen therapy conditions. The short duration of sessions in our study may explain the lack of differences in comfort, as longer durations are needed for the emergence of adverse experiences such as upper airway dryness caused by the high- $\mathrm{F}_{\mathrm{IO}_{2}}$ face mask, ${ }^{26}$ intolerance to $\mathrm{CPAP},{ }^{19}$ or noise with HFNC. ${ }^{34}$ However, contrary to this result, 75\% of our subjects found that HFNC was more pleasant than the other oxygen delivery techniques (CPAP and high$\mathrm{F}_{\mathrm{IO}_{2}}$, non-rebreathing face mask). In clinical practice, Sztrymf et al ${ }^{15,16}$ reported a remarkable tolerance of HFNC over longer use. This excellent tolerance, systematically reported with HFNC during acute hypoxemic failure, $4,15,16$ is attributable, at least in part, to the heat and humidity supplied by the device. ${ }^{35} \mathrm{We}$ reported a case of prolonged HFNC use for over $30 \mathrm{~d} .^{36}$

\section{Dyspnea Score}

All studies performed in subjects with acute hypoxemic respiratory failure showed significant improvement in clinical parameters with HFNC compared with standard face mask oxygen therapy. ${ }^{4,15,16}$ However, in our study, even though HFNC distinctly improved dyspnea, the improvement was not statistically significant. Two hypotheses exist: first, although none of our subjects had delirium, the visual analog scale used in our study was subjective, and second, the study may have been underpowered.

\section{Limitations of This Study}

This study was designed to determine the physiologic short-term effects of HFNC and did not seek to assess their 
impact on outcome. However, the findings provide a convincing physiologic explanation to the results of some clinical trials. Neither the subjects nor the investigators were blinded to the oxygen delivery devices. This may have biased the results, although this was minimized by the fact that study periods were performed in a random order. Only one type of HFNC device was used in this study. Nonetheless, the results regarding subject effort or $\mathrm{P}_{\mathrm{aO}_{2}} / \mathrm{F}_{\mathrm{IO}_{2}}$ would probably be similar with other HFNC devices. We used the largest cannula tolerable for each individual; however, we were not able to quantify leaks around the nose. The PAP generated by HFNC appears to be flow-dependent, so we used the highest possible flow $(60 \mathrm{~L} / \mathrm{min})$. However, we cannot assert that the results (in terms of inspiratory effort or oxygenation) would be similar with a different setting. We did not record the flow signal or gastric pressure. This is another limitation of our study in the assessment of inspiratory effort.

\section{Conclusions}

In summary, the results of this provide new physiologic guidance for selecting oxygen therapy devices in patients with acute hypoxemic respiratory failure. The findings are of clinical relevance because they show that, in such subjects, HFNC provided a better physiologic response in terms of muscle unloading and oxygenation than conventional oxygen given through a high- $\mathrm{F}_{\mathrm{IO}_{2}}$, non-rebreathing face mask. However, in our study, oxygenation improvement was better, with a CPAP of $5 \mathrm{~cm} \mathrm{H}_{2} \mathrm{O}$. HFNC could be an alternative to conventional oxygen therapy in patients with acute respiratory failure, but further studies are needed to specify the place of HFNC in the strategy of treatment for these patients.

\section{ACKNOWLEDGMENTS}

We are grateful to the junior doctors, nursing staff, and our clinical research associate Marie-Pierre Baudier. We thank Patrick McSweeny for stylistic editing of the manuscript.

\section{REFERENCES}

1. Kallstrom TJ. AARC Clinical Practice Guideline: oxygen therapy for adults in the acute care facility-2002 revision \& update. Respir Care 2002;47(6):717-720.

2. Wagstaff TA, Soni N. Performance of six types of oxygen delivery devices at varying respiratory rates. Anaesthesia 2007;62(5):492503.

3. L'Her E, Deye N, Lellouche F, Taille S, Demoule A, Fraticelli A, et al. Physiologic effects of noninvasive ventilation during acute lung injury. Am J Respir Crit Care Med 2005;172(9):1112-1118.

4. Roca O, Riera J, Torres F, Masclans JR. High-flow oxygen therapy in acute respiratory failure. Respir Care 2010;55(4):408-413.

5. Parke RL, McGuinness SP, Eccleston ML. A preliminary randomized controlled trial to assess effectiveness of nasal high-flow oxygen in intensive care patients. Respir Care 2011;56(3):265-270.
6. Groves N, Tobin A. High flow nasal oxygen generates positive airway pressure in adult volunteers. Aust Crit Care 20(4)07;20:126-131.

7. Parke R, McGuinness S, Eccleston M. Nasal high-flow therapy delivers low level positive airway pressure. Br J Anaesth 2009;103(6): 886-890.

8. Corley A, Caruana LR, Barnett AG, Tronstad O, Fraser JF. Oxygen delivery through high flow nasal cannulae increase end expiratory lung volume and reduce respiratory rate in post-cardiac surgical patients. Br J Anaesth 2011;107(6):998-1004.

9. Chanques G, Riboulet F, Molinari N, Carr J, Jung B, Prades A, et al. Comparison of three high flow oxygen therapy devices: a clinical physiological cross-over study. Minerva Anestesiol 2013;79(12): 1344-1355.

10. Shepard JW Jr, Burger CD. Nasal and oral flow-volume loops in normal subjects and patients with obstructive sleep apnea. Am Rev Respir Dis 1990;142(6 Pt 1):1288-1293.

11. Dysart K, Miller TL, Wolfson MR, Shaffer TH. Research in high flow therapy: mechanisms of action. Respir Med 2009;103(10):14001405.

12. Chatila W, Nugent T, Vance G, Gaughan J, Criner GJ. The effects of high-flow vs low-flow oxygen on exercise in advanced obstructive airways disease. Chest 2004;126(4):1108-1115.

13. Wettstein RB, Shelledy DC, Peters JI. Delivered oxygen concentrations using low-flow and high-flow nasal cannulas. Respir Care 2005; 50(5):604-609.

14. Mündel T, Feng S, Tatkov S, Schneider H. Mechanisms of nasal high flow on ventilation during wakefulness and sleep. J Appl Physiol 2013;114(8):1058-1065.

15. Sztrymf B, Messika J, Mayot T, Lenglet H, Dreyfuss D, Ricard JD. Impact of high-flow nasal cannula oxygen therapy on intensive care unit patients with acute respiratory failure: a prospective observational study. J Crit Care 2012;27(3):324.e9-324.e913.

16. Sztrymf B, Messika J, Bertrand F, Hurel D, Leon R, Dreyfuss D, Ricard JD. Beneficial effects of humidified high flow nasal oxygen in critical care patients: a prospective pilot study. Intensive Care Med 2011;37(11):1780-1786.

17. Itagaki T, Okuda N, Tsunano Y, Kohata H, Nakataki E, Onodera M, et al. Effect of high flow nasal cannula on thoraco-abdominal synchrony in adults critically ill patients. Respir Care 2014;59(1):70-74.

18. Maggiore SM, Idone FA, Vaschetto R, Festa R, Cataldo A, Antonicelli $\mathrm{F}$, et al. Nasal high-flow versus Venturi mask oxygen therapy after extubation. Effects on oxygenation, comfort, and clinical outcome. Am J Respir Crit Care Med 2014;190(3):282-288.

19. Delclaux C, L'Her E, Alberti C, Mancebo J, Abroug F, Conti G, et al. Treatment of acute hypoxemic nonhypercapnic respiratory insufficiency with continuous positive airway pressure delivered by a face mask: a randomized controlled trial. JAMA 2000; 284(18):2352-2360.

20. Diehl JL, Lofaso F, Deleuze P, Similowski T, Lemaire F, Brochard L. Clinically relevant diaphragmatic dysfunction after cardiac operations. J Thorac Cardiovasc Surg 1994;107(2):487-498.

21. Baydur A, Behrakis PK, Zin WA, Jaeger M, Milic-Emili J. A simple method for assessing the validity of the esophageal balloon technique. Am Rev Respir Dis 1982;126(5):788-791.

22. Vargas F, Thille A, Lyazidi A, Campo FR, Brochard L. Helmet with specific settings versus facemask for noninvasive ventilation. Crit Care Med 2009;37(6):1921-1928

23. Fontanari P, Burnet H, Zattara-Hartmann MC, Jammes Y. Changes in airway resistance induced by nasal inhalation of cold dry, dry, or moist air in normal individuals. J Appl Physiol 1996;81(4):1739-1743.

24. Richards GN, Cistulli PA, Ungar RG, Berthon-Jones M, Sullivan CE. Mouth leak with nasal continuous positive airway pressure increases nasal airway resistance. Am J Respir Crit Care Med 1996; 154(1):182-186. 
25. Chikata Y, Izawa M, Okuda N, Itagaki T, Nakataki E, Onodera M, et al. Humidification performances of two high flow nasal cannula devices: a bench study. Respir Care 2014;59(8):1186-1190.

26. Chanques G, Constantin JM, Sauter M, Jung B, Sebbane M, Verzilli D, et al. Discomfort associated with underhumidified high flow oxygen therapy in critically ill patients. Intensive Care Med 2009; 35(6):996-1003.

27. Frat JP, Brugiere B, Ragot S, Chatellier D, Veinstein A, Goudet V, et al. Sequential application of oxygen therapy via high-flow nasal cannula and noninvasive ventilation in acute respiratory failure: an observational pilot study. Respir Care 2015;60(2):170-178.

28. Hinz J, Hahn G, Neumann P, Sydow M, Mohrenweiser P, Hellige G, Burchardi H. End expiratory lung impedance change enables bedside monitoring of end-expiratory lung volume change. Intensive Care Med 2003;29(1):37-43.

29. van Genderingen HR, van Vught AJ, Jansen JR. Estimation of regional lung volume changes by electrical impedance pressures tomography during a pressure-volume maneuver. Intensive Care Med 2003;29(2):233-240.

30. Katz JA, Marks JD. Inspiratory work with and without continuous positive airway pressure in patients with acute respiratory failure. Anesthesiology 1985;63(6):598-607.
31. Lin M, Yang YF, Chiang HT, Chang MS, Chiang BN, Cheitlin MD. Reappraisal of continuous positive airway pressure therapy in acute cardiogenic pulmonary oedema: short-term results and long-term follow-up. Chest 1995;107(5):1379-1386.

32. Lenique F, Habis M, Lofaso F, Dubois-Randé JL, Harf A, Brochard L. Ventilatory and hemodynamic effects of continuous positive airway pressure in left heart failure. Am J Respir Crit Care Med 1997; 155(2):500-505.

33. Ricard JD. High flow nasal oxygen in acute respiratory failure. Minerva Anestesiol 2012;78(7):836-841.

34. König K, Stock EL, Jarvis M. Noise levels of neonatal high-flow nasal cannula devices_-an in-vitro study. Neonatology 2013;103(4): 264-267.

35. Cuquemelle E, Pham T, Papon JF, Louis B, Danin PE, Brochard L. Heated and humidified high-flow oxygen therapy reduces discomfort during hypoxemic respiratory failure. Respir Care 2012;57(10):15711577.

36. Boyer A, Vargas F, Delacre M, Saint-Léger M, Clouzeau B, Hilbert G, Gruson D. Prognostic impact of high-flow nasal cannula oxygen supply in an ICU patient with pulmonary fibrosis complicated by acute respiratory failure. Intensive Care Med 2011;37(3):558-559.

This article is approved for Continuing Respiratory Care Education credit. For information and to obtain your CRCE

(free to AARC members) visit

www.rcjournal.com 